\title{
Concept and Dimensions of Web 4.0
}

\author{
Fernando Almeida \\ Associate Professor, Faculty of Engineering of Oporto University, INESC TEC, Porto, Portugal
}

\begin{abstract}
Web 4.0 is a new evolution of the Web paradigm based on multiple models, technologies and social relationships. The concept of Web 4.0 is not totally clear and unanimous in literature, because it is composed by several dimensions. In this sense, this study uses a systematic review approach to clarify the concept of Web 4.0 and explore its various dimensions, analyzing if they have elements in common. The findings indicate that the number of studies published from 2009 to 2017 on this field significantly increased, having reached a peak in 2014. Furthermore, we identified five dimensions associated with the Web 4.0 paradigm, in which the terms "pervasive computing" and "ubiquitous computing" are the most widely used in the literature. On the other side, terms such as "Web 4.0", "symbiotic Web" and "Web social computing" are not often used.
\end{abstract}

\section{Indexing Terms/Keywords}

Web 4.0, Symbiotic Web, Web of Things, Web social computing, Pervasive computing, Ubiquitous computing

\section{Academic Discipline and Sub-Disciplines}

Information Systems

\section{SUBJECT CLASSIFICATION}

Technology

\section{TYPE (METHOD/APPROACH)}

\author{
Systematic Review
}

\section{INTRODUCTION}

The Web, despite being a relatively young communication channel, has been marked by several generations with very short cycles. The evolution of the Web has been sustained by the strong speed of the growth of technology. Today, the Web offers a rapid diffusion channel of information and knowledge, allowing companies not only to improve their efficiency but also to offer new products and services to their customers. In addition, consumers also have a channel of excellence to communicate with companies, to express their opinions about products and services, and to interact with other consumers.

Firstly appeared the Web 1.0 that can be defined as the first phase of the Web, and which extends fundamentally during the 90 's. Web 1.0 is characterized by being a read-only Web, in which the user assumes a passive position as a mere viewer, without being able to develop and post content on the visited sites.

The second phase of the Web, popularly known as Web 2.0, appeared between the years of 2000 to 2009 . With Web 2.0 came the revolution of social networks, high interactivity and user participation in the content production. At that time, we assisted to the appearance of very popular websites such as Wikipedia, Facebook, Youtube, Twitter or Instagram. Web sites became interactive, providing feedback and encouraging user participation. Mobile access to the Web has grown significantly and the concept of SEO has emerged.

The third phase of the Web, known as Web 3.0 or Semantic Web, extends from 2010 to 2019 . Web 3.0 intends to organize how content is searched and viewed by the user. The goal is to customize and optimize the online search, based on the history, interests and wishes of users. Web 3.0 is also called by several authors as the intelligent Web, since its functionalities extend beyond the traditional search services. For example, in Web 3.0 advertisements can be customized according to each user's behavior and preferences.

Currently, we find that both versions of the Web coexist. Furthermore, some authors suggest that the birth of a new phase of the Web, entitled Web 4.0, is at an early stage. This study intends to clarify the concept of Web 4.0 and analyze its dimensions, since there are quite different approaches about what is or it can be the Web 4.0. In this sense, we adopt a systematic literature review approach to identify the several concepts, dimensions and trends associated with Web 4.0 . The paper is organized as follows: First, the most relevant related studies on the field of Web 4.0 are analyzed. Then, the several steps of the methodology are presented, followed by the presentation and discussion of the results. Finally, the conclusions of the work are drawn.

\section{RELATED WORK}

Hendler and Berners-Lee [1] were the first authors to identify the emergence of a new Web paradigm. They advocate that the advent of social computing on the Web originated the appearance of a new era entitled "social machines". They consider that currently we need to interact with new Web applications that deal with large volumes of data, which cannot be exclusively supported in a human analysis. Shadbolt, Kleek, and Binns [2] state that "social machines" will have the 
mission to invisibly orchestrate our social processes. In this sense, it becomes necessary a greater collaboration between researchers in the fields of Web and artificial intelligence.

Pervasive computing or ubiquitous computing refers to a new era of computing, where diverse computing elements will be integrated, such as desktops, sensors, mobile devices, appliances, electronic equipments, etc. All these devices will be used in offices, in factories, in clothing and day-to-day life. A crucial element of pervasive computing will be the high level of communication between the various participating devices and sensors, which will enable a synchronized, secure and communicated infrastructure [3]. Shaheed, Abbas, Shabbir, and Khalid [4] state that other decisive element for its largescale adoption is the existence of security mechanisms.

Web 4.0 emerges as a new Web generation and it is defined by several authors in different ways. Davis [5] state that Web 4.0 will bring together all aspects of Web 2.0 and Web 3.0 to become truly ubiquitous. Khoo [6] and Perera, Zaslavsky, Christen, and Georgakopoulos [7] associate Web 4.0 to the concept of Internet of Things. On the same direction, White [8] establishes that Web 4.0 is the same as Web of Things, which is a subset of the general concept of Internet of Things. Polanska [9] predicts that Web 4.0 will be based on a universal web personality of each user, where the information flow will be highly personalized. She also expects that user anonymity will be impossible in Web 4.0. Kambil [10] defines Web 4.0 as a mobile space where users, real and virtual objects are integrated together to create value. Weber and Rech [11] relate Web 4.0 to the concept of augmented reality considering that the evolution of this technology will enrich real world with digital information and media contents. On the other hand, Martínez-Lopez, Anaya-Sánchez, Aguillar-Illescas, and Molinillo [12] associate the concept of Emotive Web to Web 4.0, where the user shares his/her emotions online using social networks. Aghaei, Nematbakhsh, and Farsani [13] and Bauman and Bachmann [14] associate the concept of Web 4.0 to symbiotic Web, considering that individuals and commercial enterprises are mutually dependent.

There are also studies that link the Web 4.0 concept to a diverse set of elements. Choudhury [15] also highlights the importance of the symbiotic Web in the definition of Web 4.0, but adds two more components: (i) ultra-intelligent electronic agents; and (ii) ubiquitous Web. Korhonen and Karhu [16] state that the essence of Web 4.0 is based on automatic reasoning, sustained by the advances in artificial intelligence and the large-scale use of linked agents. Parvathi and Mariselvi [17] predict the appearance of Web 4.0 in 2020-2030 and associate four technologies to its concept: (i) artificial intelligence; (ii) nanotechnology; (iii) telecommunications; and (iv) controlled interfaces. On the other hand, Nedeva and Dineva [18] associate the concept of Web 4.0 to the following three technologies: (i) intelligent agents; (ii) mobile technologies; and (iii) cloud computing services. Murugesan, Rossi, Wilbanks, and Djavanshir [19] state that Web 4.0 will be smarter and more collaborative, and based on the agent-centered paradigm. A similar vision is shared by SołtysikPiorunkiewicz [20], which state that Web will evolve towards a more knowledge base with the adoption of agent oriented systems. Nath and Iswary [21] suggest that Web 4.0 will be based on three main concepts: (i) natural language understanding (NLU) technique; (ii) new model of communication between machine to machine (M2M); and (iii) new model of interface.

There are also studies linking the future evolution of the Web to the large-scale adoption of the big data by companies, public institutions and society [22-24]. In this sense, the big data would be used to collect information in real time, from internal and external sources (which includes the Web). In such scenario big data will help companies to understand the environment of their business and identify possible changes that may occur, in order to create new products and services.

Krumova, Paunova, and Yotova [25] look at the impact of adoption of open and linked data in business and marketing practices. They identify five generations of Web, with the following characteristics: (i) Web 4.0 is seen a symbiosis interaction between humans and machines; (ii) and Web 5.0 is referred as a web of decentralized smart communicator. Benito-Osorio, Peris-Ortiz, Armengot, and Colino [26] predict Web 5.0 as the sensory and emotive Web. Khanzode and Sarode [27] introduce a new Web generation, entitled Web 6.0, in which web service extensions will deploy the role of serving dynamic content in web servers, such as IIS or Apache.

Finally, associated with the role of Web 4.0 appears the concept of Industry 4.0. It is an industrial concept recently emerged that encompasses the main technological innovations in the fields of automation, control and information technology applied to manufacturing processes [28-30]. From the concepts of cyber-physical systems, Web services and loT, production processes tend to become increasingly efficient, autonomous and customizable. The main goal is the creation of smart factories that could be increasingly efficient, yet simultaneously interactive, highly dynamic and reactive to changes in external environments [31-32]

In summary, too few studies look at the Web 4.0 paradigm, and there aren't systematic reviews on this field. Most of them associate the concept of Web 4.0 to a very diverse number of concepts and technologies. Therefore, we consider our work to be an important reference to clarify the concept of Web 4.0 and its associated dimensions.

\section{METHODOLOGY}

This study has been undertaken as a systematic literature review based on five steps approach proposed by Khan, Kunz, Kleijnen, and Antes [33]. These five steps include: (i) framing questions for a review; (ii) identifying relevant work; (iii) assessing the quality of studies; (iv) summarizing the evidence; and (v) interpreting the findings. Fig. 1 depicts the research activities performed along the systematic literature review. 


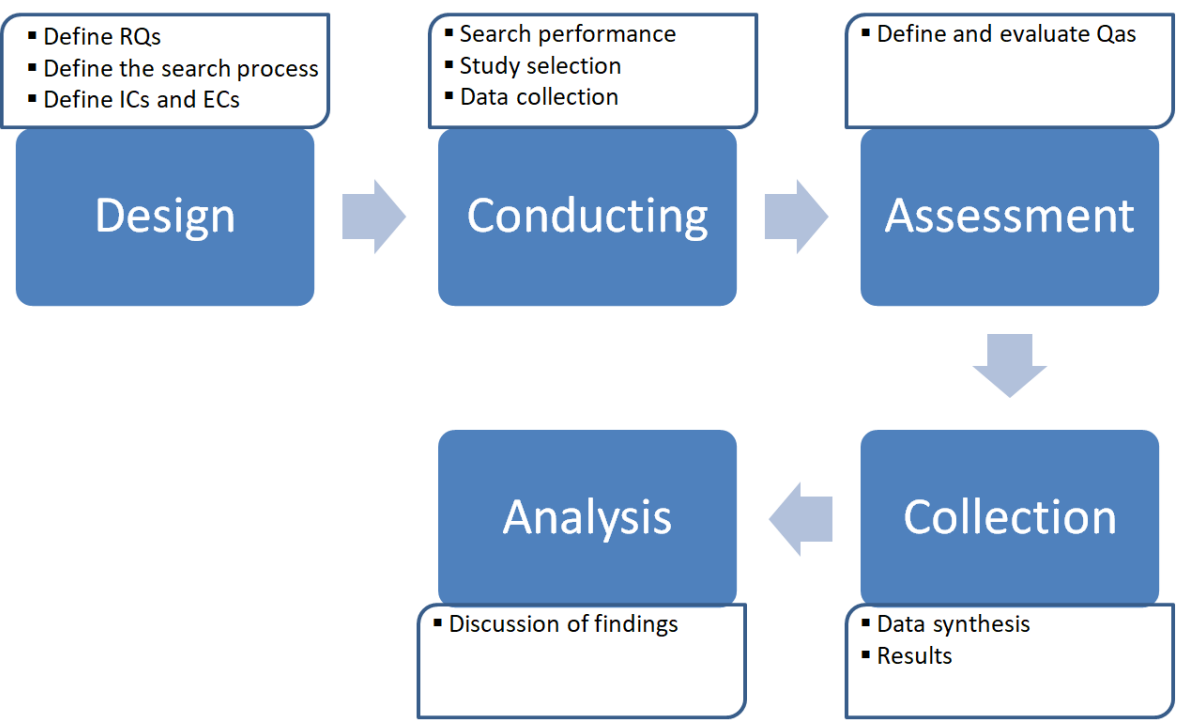

Fig 1: Research activities

\section{Research questions}

In order to clarify and identify the several dimensions of the Web 4.0 paradigm we addressed two main research questions:

○ RQ1. How many studies on Web 4.0 have been published since 2009 ?

○ RQ2. What concepts and research topics are associated with Web 4.0?

With respect to RQ1, it may be noticed that we only started our analysis on 2009. The first study that identifies a paradigm shift from Web 3.0 to a new Web paradigm was conducted by Hendler and Berners-Lee [1] on that year. Finally, with respect to RQ2, we considered all research topics related to the subjects in the field of computer science, software engineering and information systems.

\section{Search process}

Several heterogeneous and complementary sources of information were selected, respectively: (i) scientific journals; (ii) conference proceedings; (iii) books; and (iv) book chapters. The research involved the use of the INSPEC database and the Amazon library. Used search terms took into consideration the various elements present in the definition of the Web 4.0 concept, as described in "Related Work" section. Therefore, the following search terms were included: (i) Web 4.0; (ii) Web social computing; (iii) Web of Things; (iv) symbiotic Web; (v) pervasive Web; and (iv) ubiquitous Web. The search strings were used in the digital libraries based on the title and keywords of each document.

\section{Quality assessment}

In order to ensure the robustness of the process we defined a set of inclusion and exclusion criteria (Fig. 2). Furthermore, we detected and avoided double counting of the same item. Additionally, only publications with peer review were accepted, except in the case of books.

Inclusion criteria
- English language studies
- Peer review studies
including: conference
proceedings, journals and
book chapters
- Published books available
in Amazon library
- Studies that focus in Web
4.0 paradigm
- Studies published since
2009

\section{Exclusion criteria}

- Non-english language studies

- Studies that are not related to the research topic

- Duplicated studies

- Technical reports

- Thesis

- Magazines, news and blogs

Fig 2: Inclusion and exclusion criteria 


\section{Data collection}

The following elements were extracted from each study:

○ The type of the document (e.g., journal, conference proceeding, book, etc.);

○ The reference of each document;

- Research question/issue;

- Summary of the definition of Web 4.0 concept;

○ List of dimensions associated with Web 4.0.

\section{Data analysis}

The following elements of analysis were adopted:

- Number of studies published per year and type (addressing RQ1);

- The terms associated to Web 4.0 definition (addressing RQ2);

- The several dimensions associated to Web 4.0 paradigm (addressing RQ2).

\section{ANALYSIS AND DISCUSSION OF RESULTS}

Fig. 3 synthesizes the evolution of the number of publications in journals, conferences proceedings, books, and book chapters since 2009 in the field of Web 4.0. A total of 886 publications were found. The publication in conferences is the one that assumes most relevance with 368 items (41,53\%), followed by journals with 351 papers $(39,62 \%)$, book chapters with 104 articles $(11,74 \%)$, and books with 63 items (7,11\%). Despite the greater weight of publications considering all years, its relative importance has declined since 2014 when it reached its peak. On the contrary, publications in international journals since 2013 have experienced significant and sustainable growth in subsequent years. Two reasons may justify this behavior: (i) the decrease in the number of publications in international conferences in recent years, due to financial restrictions experienced by several universities; and (ii) the maturation of Web 4.0 concepts, technologies and processes. Finally, it should be mentioned that only indexed publications until the end of October 2017 were considered. Therefore, it is not possible to get precise conclusions about the behavior of publication for this year.

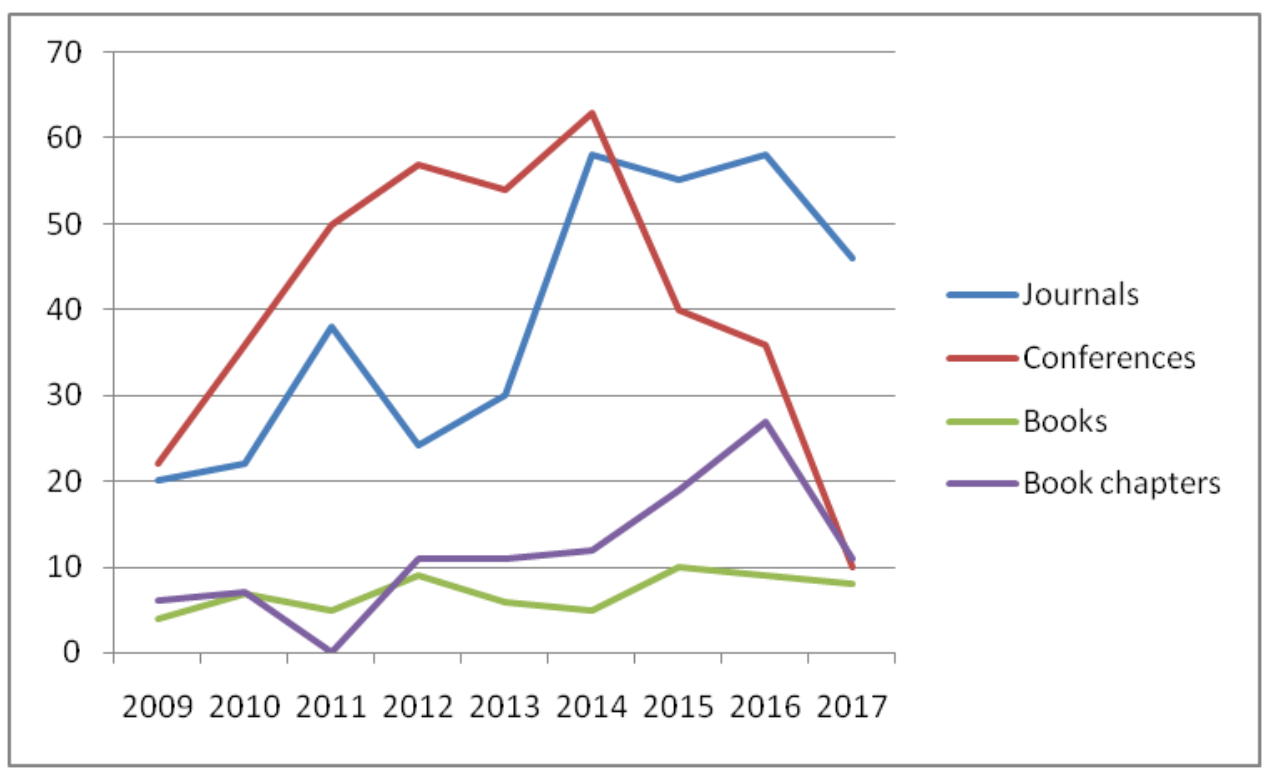

Fig 3: Publications in the field of Web 4.0 since 2009

The relevance of each term associated with the Web 4.0 paradigm was also analyzed. The findings, depicted in Table 1, indicate that the simple designation of "Web 4.0 " is not a term widely used in most studies, representing only around $2 \%$. On the whole, the term "symbiotic Web" is the one that has less predominance. On the contrary, the "pervasive computing" and "ubiquitous computing" terms are the most widely used, representing more than $75 \%$ of the published studies. 
Table 1. Associated terms with Web 4.0 paradigm

\begin{tabular}{|c|c|c|}
\hline Terms & Number of items & Percentage \\
\hline Web 4.0 & 19 & $2,14 \%$ \\
\hline Symbiotic Web & 2 & $0,23 \%$ \\
\hline Web of Things & 158 & $17,83 \%$ \\
\hline Web social computing & 36 & $4,06 \%$ \\
\hline Pervasive computing & 354 & $39,95 \%$ \\
\hline Ubiquitous computing & 317 & $35,78 \%$ \\
\hline
\end{tabular}

In order to characterize the concepts and several dimensions associated to Web 4.0 we used the Strategic Options Development and Analysis (SODA) method. It is a method for working on complex problems. SODA uses the cognitive map concept and helps in the process of understanding, capturing and managing a complex and multi-dimensional process [34]. In this sense, it is appropriate to use this method in innovative and poorly explored areas of knowledge about which it is necessary to analyze several components and interconnection between them. In our study, this method becomes perfectly adequate, since the Web 4.0 paradigm has several dimensions that have distinct and common elements.

Fig. 4 presents the conceptual map built on the Web 4.0 paradigm using the SODA method. Five dimensions were identified: (i) symbiotic Web; (ii) Web of Things; (iii) Web social computing; (iv) pervasive Web; and (v) ubiquitous computing. Each dimension shares several elements in common. Ubiquitous computing and pervasive Web share exactly the same elements, hence these two terms can be understood as synonyms in the context of this work. Other common elements are shared between the "Web of Things" and "Web social computing", namely the need to apply Big Data algorithms and the emergence of M2M communications that come from the use of Internet of Things and artificial intelligence.

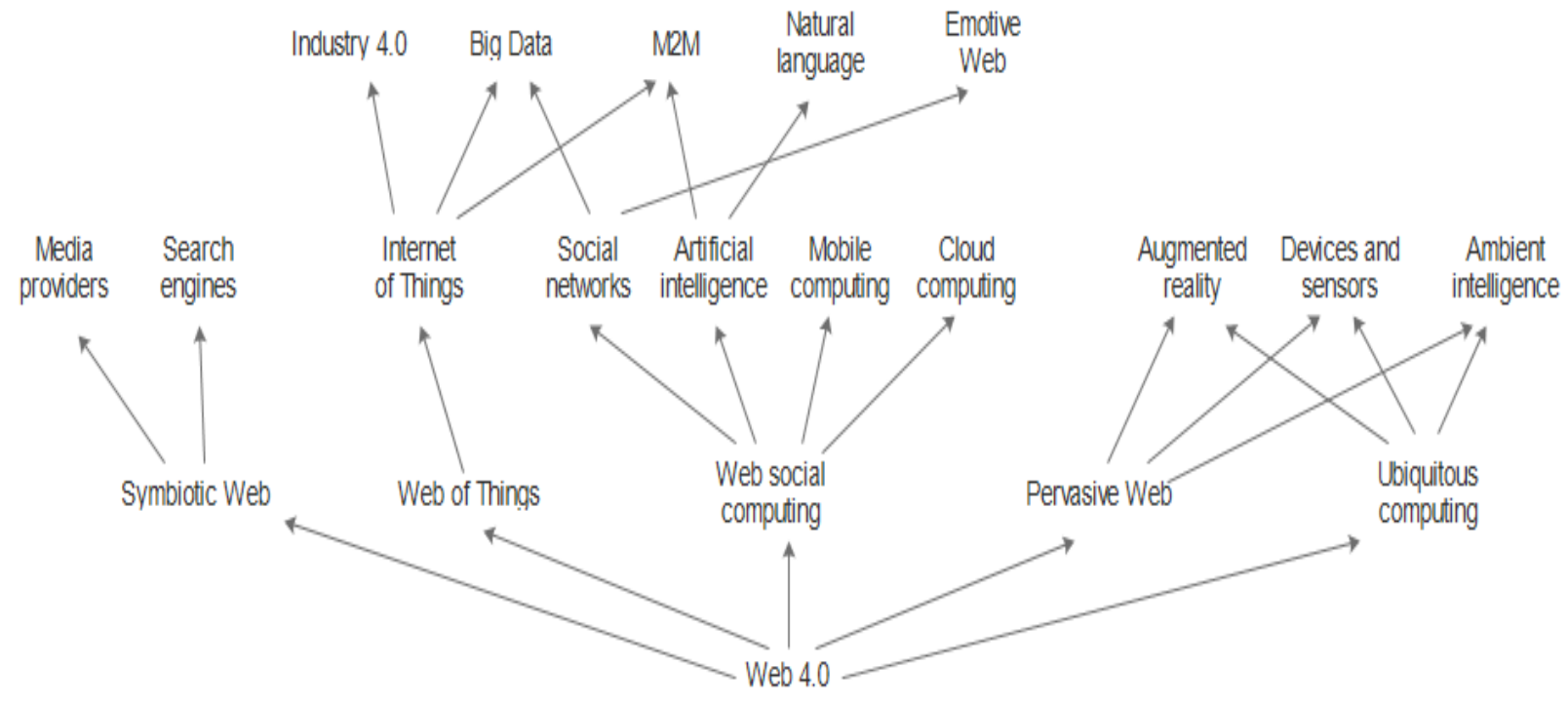

Fig 4: SODA representation of Web 4.0

\section{CONCLUSIONS}

The Web is continuously evolving. Over the last years, new technologies have emerged to provide users with the ability to live increasingly interactive and immersive experiences. In this regards, the growing awareness of wireless networks, the growing presence of smartphones and tablets, have made the Internet more ubiquitous. Additionally, the access to the Internet is not made exclusively by humans, but also from other physical objects, devices and vehicles, originating the concept of Internet of Things. These new realities led to the emergence of a new Web paradigm, entitled Web 4.0.

The concept of Web 4.0 is quite irregular and mutable. Since 2009, several definitions of the Web 4.0 have been suggested by numerous authors. However, there isn't a totally consensus regarding a solid definition of Web 4.0, contrarily to previous wide-accepted definitions of Web 1.0, Web 2.0 and Web 3.0. In this sense, it can be stated that Web 4.0 covers a set of multiples dimensions. Each of these dimensions offers a distinct, but simultaneously comprehensive, view of the Web 4.0 paradigm. It stands out that applications such as social networks, and technologies such as Internet of Things, Big Data, artificial intelligence and M2M play a key role in the adoption and implementation of Web 4.0. 


\section{REFERENCES}

[1] Hendler, J, and Berners-Lee, T. 2010. From the Semantic Web to social machines: A research challenge for Al on the World Wide Web. Artificial Intelligence, 174, 156-161.

[2] Shadbolt, N., Kleek, M., and Binns, R. 2016. The Rise of Social Machines. IEEE Consumer Electronics Magazine, April, 106-111.

[3] Bhasker, L. 2013. Pervasive Computing Issues, Challenges and Applications. International Journal of Engineering and Computer Science (IJECS), 2(12), 3337-339.

[4] Shaheed, S., Abbas, J., Shabbir, A., and Khalid, F. 2015. Solving the Challenges of Pervasive Computing. Computer Science \& Communications (JCC), 3(9), 41-50.

[5] Davis, M. 2010. Semantics + Gov 2.0 - Where are web 3.0, semantic technologies, and the next internet taking us? Meta 2009. Institute of Metadata Management, Australian National University, Canberra.

[6] Khoo, B. 2010. Rfid- from tracking to the internet of things: A review of developments. In Proceedings of the 2010 IEEE/ACM International Conference on Green Computing and Communications, Washington, USA, 533-538.

[7] Perera, C., Zaslavsky, A., Christen, P, and Georgakopoulos, D. 2014. IEEE Communications Surveys \& Tutorials, 16(1), 414-454.

[8] White, B. 2015. Discovering the Future of the Web. Journal of Computing and Information Technology, 23(1), 87-93.

[9] Polanska, K. 2014. Social Media in Modern Business. European Scientific Journal, 1(1), 335-345.

[10] Kambil, A. 2008. What is your Web 5.0 strategy? Journal of Business Strategy, 29(6), 56-58.

[11] Weber, S., and Rech, J. 2010. An overview and differentiation of the evolutionary steps of the Web X.Y movement: The Web before and beyond 2.0. In Murugesan, S. (Ed.), Handbook of Research on Web 2.0, 3.0, and X.0 technologies, business and social applications (pp. 12-38), Hershey, PA: IGI Global.

[12] Martínez-Lopez, F., Anaya-Sánchez, R., Aguilar-Illescas, R., and Molinillo, S. 2016. Online Brand Communities. Gewerbestrasse, Switzerland: Springer International Publishing.

[13] Aghaei, S., Nematbakhsh, M., \& Farsani, H. 2012. Evolution of the World Wide Web: From WEB 1.0 To WEB 4.0. International Journal of Web \& Semantic Technology, 3(1), 1-10.

[14] Bauman, A., and Bachmann, R. 2017. Online Consumer Trust: Trends in Research. Journal of Technology Management \& Innovation, 12(2), 68-79.

[15] Choudhury, N. 2014. World Wide Web and Its Journey from Web 1.0 to Web 4.0. International Journal of Computer Science and Information Technologies, 5(6), 8096-8100.

[16] Korhonen, J., and Karhu, K. 2011. Explaining the Evolutionary Development of the Web. In E. Gummesson, C. Mele, \& F. Polese (Eds.), The 2011 Naples Forum on Service - Service Dominant logic, Network \& Systems Theory and Service Science: integrating three perspectives for a new service agenda, Capri, Italy, June 14-17, 2011 Giannini, Napoli.

[17] Parvathi, M., and Mariselvi, R. 2017. A bird's eye on the evolution - Web 1.0 to Web 5.0: Lib 1.0 to Lib 5.0. International Journal of Advanced Research Trends in Engineering and Technology (IJARTET), 4(4), 167-176.

[18] Nedeva, V., and Dineva, S. 2012. New learning innovations with Web 4.0. In Proceedings of the 7th International Conference on Virtual Learning (ICVL), Bucharest, Romania, 316-321.

[19] Murugesan, S., Rossi, G., Wilbanks, L, and Djavanshir, R. 2011. The Future of Web Apps. IT Pro, September/October, 12-14.

[20] Sołtysik-Piorunkiewicz, A. 2013. The development of mobile Internet technology and ubiquitous communication in a knowledge-based organization. Online Journal of Applied Knowledge Management, 1(1), 29-41.

[21] Nath, K., and Iswary, R. 2015. What comes after Web 3.0? Web 4.0 and the Future. In Proceedings of the International Conference and Communication System (I3CS'15), Shillong, India, 337-341.

[22] Provost, F., and Fawcett, T. 2013. Data Science and its Relationship to Big Data and Data-Driven Decision Making. Big Data, 1(1), 51-59.

[23] Henke, N., Bughin, J., Chui, M., Manyika, J., Saleh, T., Wiseman, B., and Sethupathy, G. 2016. The age of analytics: Competing in a data-driven world. McKinsey Global Institute Report, December, 1-136.

[24] Almeida, F. 2017. Benefits, Challenges and Tools of Big Data Management. Journal of Systems Integration, 8(4), 12 20.

[25] Krumova, M., Paunova, L., and Yotova, S. 2017. Open and Linked Data in Business: Disruptive Marketing Mix 3.0. Journal of Management and Innovation, 3(1), 1-19.

[26] Benito-Osorio, D., Peris-Ortiz, M., Armengot, C., and Colino, A. 2013. Web 5.0: the future of emotional competences in higher education. Global Business Perspectives, 1(3), 274-287. 
[27] Khanzode, K., and Sarode, R. 2016. Evolution of the World Wide Web: From Web 1.0 to 6.0. International Journal of Digital Library Services, 6(2), 1-11.

[28] Almada-Lobo, F. 2015. The Industry 4.0 revolution and the future of Manufacturing Execution Systems (MES). Journal of Innovation Management, 3(4), 16-21.

[29] Roblek, V., Mesko, M., and Krapez, A. 2016. A Complex View of Industry 4.0. SAGE Open, April-June, 1-11.

[30] Rojko, A. 2017. Industry 4.0 Concept: Background and Overview. International Journal of Interactive Mobile Technologies, 11(5), 77-90.

[31] Sheladiya, M., Acharya, S., and Acharya, G. 2017. Internet of Things (IoT) - A Step toward Foundry 4.0. Journal of Web Engineering \& Technology, 4(2), 31-34.

[32] Lee, J., Jun, S., Chang, T., and Park, J. 2017. A Smartness Assessment Framework for Smart Factories Using Analytic Network Process. Sustainability, 9(5), 1-15.

[33] Khan, K., Kunz, R., and Kleijnen, J. 2003. Five steps to conducting a systematic review. Journal of the Royal Society of Medicine (JRSM), 96(3), 118-121.

[34] Ackermann F., and Eden C. 2010. Strategic Options Development and Analysis. In: Reynolds M., Holwell S. (eds), Systems Approaches to Managing Change: A Practical Guide. Springer, London.

\section{Author' biography with Photo}

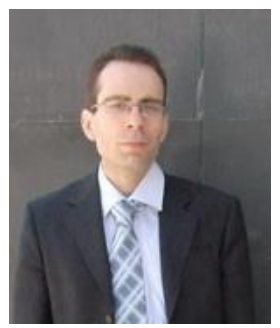

Fernando Luís Almeida has a PhD in Computer Science Engineering from Faculty of Engineering of University of Porto (FEUP). He holds also MSc in Innovation and Entrepreneurship and MSc in Informatics Engineering from FEUP. He has around 7 years of teaching experience at higher education levels in the field of computer science and management. He has also worked for 10 years in several positions as software engineer and project manager for large organizations and research centers like Critical Software, CICA/SEF, INESC TEC and ISR Porto. During that time he had the possibility to work in partnership with big international organizations and universities in several European projects. His current research areas include innovation policies, entrepreneurship, software development and web technologies.

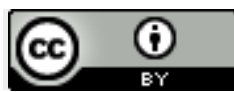

This work is licensed under a Creative Commons Attribution 4.0 International License.

DOI: $10.24297 /$ ijct.v16i7.6446 